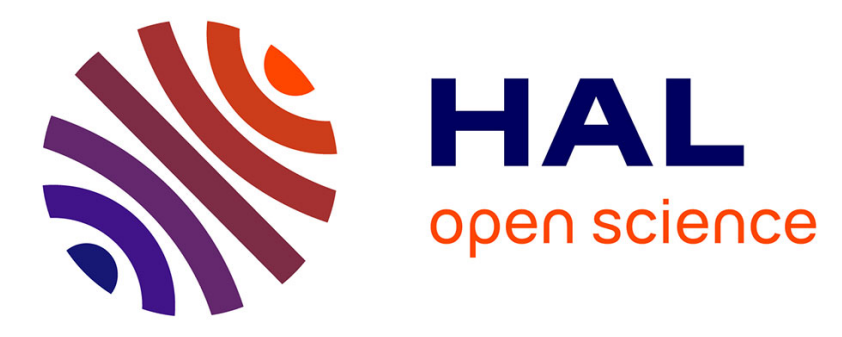

\title{
Lysophosphatidylcholine is a natural adjuvant that initiates cellular immune responses.
}

Laure Perrin-Cocon, Sophie Agaugué, Frédéric Coutant, Pierre Saint-Mézard, Aurélie Guironnet-Paquet, Jean-François Nicolas, Patrice André, Vincent Lotteau

\section{To cite this version:}

Laure Perrin-Cocon, Sophie Agaugué, Frédéric Coutant, Pierre Saint-Mézard, Aurélie GuironnetPaquet, et al.. Lysophosphatidylcholine is a natural adjuvant that initiates cellular immune responses.. Vaccine, 2006, 24, pp.1254-63. 10.1016/j.vaccine.2005.09.036 . inserm-00137028

\section{HAL Id: inserm-00137028 https://www.hal.inserm.fr/inserm-00137028}

Submitted on 16 Mar 2007

HAL is a multi-disciplinary open access archive for the deposit and dissemination of scientific research documents, whether they are published or not. The documents may come from teaching and research institutions in France or abroad, or from public or private research centers.
L'archive ouverte pluridisciplinaire HAL, est destinée au dépôt et à la diffusion de documents scientifiques de niveau recherche, publiés ou non, émanant des établissements d'enseignement et de recherche français ou étrangers, des laboratoires publics ou privés. 


\section{HAL author manuscript}

Lysophosphatidylcholine is a natural adjuvant that initiates cellular immune responses

Laure Perrin-Cocon, Sophie Agaugué, Frédéric Coutant, Pierre Saint-Mézard, Aurélie Guironnet-Paquet, Jean-François Nicolas, Patrice André and Vincent Lotteau.

Institut Fédératif de Recherche 128, Institut National de la Santé et de la Recherche Médicale U503, 21 Avenue Tony Garnier, 69007 Lyon, France

Running title: Lysophosphatidylcholine is a natural adjuvant

\section{Corresponding author:}

Dr. Laure PERRIN-COCON

INSERM U503

21 Avenue Tony Garnier

69007, Lyon, France

Tel : (33) 437282447

Fax : (33) 437282341

e-mail : perrin@cervi-lyon.inserm.fr

Key words: Adjuvant; Lysophosphatidylcholine; Lipid Mediators; Acute-phase reactants; Immunomodulators 


\begin{abstract}
The discovery of new adjuvants that can stimulate the immune response to protein antigens is a major issue for the development of subunit vaccines. Lipoprotein oxidation occurring during the acute phase response (APR) to aggression of the organism, provide signals of danger that are detected by dendritic cells (DC). Among other instructive molecules generated during the APR, lysophosphatidylcholine (LPC) promotes mature DC generation from differentiating human monocytes in vitro. It is shown here that LPC also controls the initiation of an adaptive immune response in vivo. LPC displays adjuvant properties when injected to mice in mixture with various antigens. Immunizations with LPC induced the production of antigen-specific antibodies with an efficiency similar to Alum, the reference adjuvant for human vaccination. Importantly, LPC also induced cytotoxic $\mathrm{T}$ cell responses, opening perspectives for vaccine development. Therefore, LPC is a natural adjuvant for the immune system, inducing humoral and cellular immune responses.
\end{abstract}




\section{Introduction}

With the development of new subunit vaccines that are less immunogenic than live or killed whole organism vaccines, there is an urgent need for potent adjuvants. For more than fifty years, aluminium salt derivatives (generically called Alum) have been the main adjuvants currently used for human vaccination. Toxicity is the major problem of many adjuvants that have been proposed as alternative to Alum, such as bacterial components and mineral oil emulsions. We hypothesized that endogenous lipids produced during physiological responses to aggression of the organism could be used as immunoregulators. Lipoprotein modifications occurring during the acute phase can provide signals of danger that are detected by dendritic cells (DC). The identification of these signals is a major issue to discover endogenous immunoregulators.

The acute phase response (APR) is a physiological alarm response of the body to tissue injury, trauma or infection. It is characterized by a series of coordinated processes involving several major organ systems and devoted to repair of tissue damage as well as isolation and elimination of potential pathogens. One function of the APR is to adapt the blood plasma composition to a new aggression state by transiently modifying the concentration of a number of proteins called acute phase reactants [1]. The concentration of these acute phase reactants can be increased up to a thousand fold while that of other proteins like albumin can drop dramatically [2]. This phenomenon is mainly controlled by the liver and has important consequences on lipid metabolism. It is accompanied by alterations in lipoprotein composition that result in generation of oxidized low density lipoprotein (oxLDL) and oxidized phospholipids $[3,4]$. OxLDL were first studied for their role in chronic inflammation during atherosclerosis [5] but recent work indicates that infection and inflammation also result 
in increased levels of oxLDL [6] and modified lipids that can be detected by the immune system [7-9].

Oxidative modification of low density lipoprotein (LDL) is a complex process generating numerous modified lipids such as lysophosphatidylcholine (LPC) and oxidized fatty acids that display opposite effects on inflammation. We reported that LPC downregulates the activity of the transcription factor peroxisome-proliferator activated receptor (PPAR) $\gamma$ and induce dendritic cells maturation whereas oxidized fatty acids that activate PPAR $\gamma$ inhibit DC maturation [9]. Therefore, the relative level of these lipid mediators in oxLDL appears to determine the functional properties of oxLDL. LPC can be generated by oxidation and fragmentation of the polyunsaturated sn-2 fatty acyl residues of phosphatidylcholine (PC), followed by hydrolysis of the shortened fatty acyl residues by LDL-associated enzymes [10]. LPC can also be produced by hydrolysis of PC by secretory phospholipases $\mathrm{A}_{2}\left(\mathrm{PLA}_{2}\right)$ whose secretion is strongly increased during inflammatory conditions. Importantly, LPC was recently found to be a signal produced by apoptotic cells following caspase-3 mediated activation of the intracellular calcium-independent PLA 2 [11]. LPC synthesis by apoptotic cells is a soluble attraction signal for phagocytes and can be detected by scavenger receptors and natural IgM antibodies favouring complement activation resulting in efficient elimination of apoptotic corpses [12]. Production of LPC is accompanied by anti-inflammatory mediators, especially following phosphatidylserine recognition by phagocytes, therefore quenching the pro-inflammatory activity of LPC and most likely preventing induction of immune responses. Thus, the functionally available concentration of LPC appears to be tightly controlled during the acute phase in response to tissue injury and cellular death.

LPC is implicated in many aspects of the inflammatory response. It is a potent chemoattractant for monocytes [13] phagocytes [14] and T lymphocytes [15,16]. It stimulates the expression of growth factor and adhesion molecules by endothelial cells [17-19] as well as 
their production of monocyte chemoattractant protein-1 [20]. LPC can activate monocytes and macrophages [21-25] and is one of the intracellular mediators required in the cytotoxic response of human NK cells to tumour cells [26]. After intracutaneous injection in humans, LPC induces a local inflammation and leukocyte accumulation at the site of injection [27]. LPC treatment has been shown to protect mice from experimental sepsis most likely by increasing the bactericidal activity of neutrophils [28]. LPC also displays some immunoregulatory activities. We recently reported that LPC acts through G protein-coupled receptors on differentiating monocytes to generate mature DC with the ability to stimulate IL2 and IFN $\gamma$ production by allogeneic T lymphocytes [8]. PPAR $\gamma$ are involved in this phenomenon but it is not clear whether the action of LPC on these nuclear receptors is direct or not [9]. LPC negatively regulates T cell proliferation induced by mitogenic signals [29]. Although it was first claimed that G2A could be a high affinity receptor for LPC on T lymphocytes [30], the authors now suggest that the action of LPC on G2A is indirect [31]. In mice, the production of Abs naturally generated following injection of sheep erythrocytes was increased in the presence of LPC [32]. The synthetic analogues of LPC, alkyllysophospholipids, displayed adjuvant-like properties in delayed-type hypersensitivity $[33,34]$. For these observations, no molecular target has been identified.

In this study, we asked whether LPC can initiate immune responses. Sensing the danger is a crucial function of Ag-presenting cells, that is necessary to initiate primary immune responses $[35,36]$. We previously hypothesized that oxLDL and modified phospholipids such as LPC generated during APR could signal the presence of a dangerous situation to the immune system and showed that oxLDL and LPC could favour the development of adaptive immunity by promoting mature DC generation in vitro [7-9]. It is shown here that LPC can prime both cellular and humoral Ag-specific responses, confirming that the APR regulates the production 
of critical immunoregulatory molecules by controlling the biochemical composition of lipoproteins. 


\section{Materials and Methods}

\subsection{Mice}

Female BALB/c and C57BL/6 mice (7-12 weeks of age) were obtained from Charles River Laboratories (L'Arbresle, France).

\subsection{Cell culture}

Primary cells from mouse organs were cultured in complete medium (RPMI 1640 with $2 \mathrm{mM}$ Glutamine, $10 \mathrm{mM}$ Hepes, $50 \mu \mathrm{M}$ 2-mercaptoethanol and $10 \%$ foetal calf serum) supplemented with $40 \mu \mathrm{g} / \mathrm{ml}$ Gentamycin. E.G7-OVA cells (EL-4 derived cells expressing ovalbumin (OVA)) were cultured in complete medium supplemented with $400 \mu \mathrm{g} / \mathrm{ml}$ Geneticin. E.G7-OVA cells present OVA 258-276 peptide on H-2 Kb MHC class I molecules.

\subsection{Immunization material}

Endotoxin free hen egg lysozyme (HEL) and Grade V OVA were from Sigma (St Quentin Fallavier, France) and dissolved in sterile PBS. L-alpha-lysophosphatidylcholine, complete Freund's adjuvant (CFA) and incomplete Freund's adjuvant (IFA) were from Sigma (St Quentin Fallavier, France). Alum was obtained from Pierce (Rockford, IL, USA) and used as recommended by the manufacturer. LPC was dissolved in sterile PBS for injections or in ethanol for epicutaneous applications.

Immunization mixtures were prepared by adding equal volumes of antigen (Ag) and adjuvant. To allow adsorption of $\mathrm{Ag}$ on Alum, the mixture was incubated for $30 \mathrm{~min}$ at room temperature.

\subsection{Induction of $T$ cell responses}


$\mathrm{BALB} / \mathrm{c}$ mice were immunized by injection in both hind footpads of 3 to $100 \mu \mathrm{g}$ of HEL mixed with 250 or $500 \mathrm{nmol}$ of LPC or with PBS. To analyze the effect of Intralipid (IL) on the LPC-induced T cell response, mice were immunized with a mixture containing $50 \mu \mathrm{g}$ HEL with $45 \mu 1$ Intralipid 20\% (Fresenius Kabi, Sevres, France) (HEL+IL) or $50 \mu \mathrm{g}$ HEL with $500 \mathrm{nmol}$ LPC and $45 \mu 1$ Intralipid 20\% (HEL+LPC+IL). At day 10 post-immunization, popliteal draining lymph nodes were removed and lymph nodes from the same mouse were pooled. Cells were dissociated and washed 3 times in complete medium supplemented with $40 \mu \mathrm{g} / \mathrm{ml}$ Gentamycin. Cells $\left(2.10^{6}\right.$ cells $\left./ \mathrm{ml}\right)$ were restimulated in triplicates with increasing doses of HEL for 4 days. T cell proliferation was measured by ${ }^{3} \mathrm{H}$-Thymidine incorporation added for the last $15 \mathrm{~h}$ of culture $(1 \mu \mathrm{Ci} /$ well $)$. For statistical analysis, HEL-specific proliferation indexes were calculated as the ratio between proliferation with $140 \mu \mathrm{M}$ HEL and basal proliferation without HEL. The Mann-Whitney rank test was used to compare indexes of proliferation obtained from mice immunized against HEL in the presence or not of LPC.

\subsection{Contact hypersensitivity (CHS)}

The mouse model of allergic contact dermatitis used in this study has been previously described [37]. Briefly, naïve BALB/c mice were sensitized at day 0 by epicutaneous application of $5 \mu \mathrm{l}$ of a non irritant concentration of 2,4-dinitro-fluorobenzene (DNFB) $(0.25 \%$ in acetone / olive oil $4: 1)$ on each side of the left ear. CHS developed 5 days later as a characteristic oedema. To analyze the impact of LPC on CHS reaction, one group of mice received $5 \mu 1$ of LPC ( $50 \mathrm{mM})$ dissolved in ethanol, applied on each side of the left ear at day $-2,-1$ and 0 . DNFB was applied on the same ear 15 min after the last application of LPC at day 0 (group "LPC+DNFB"). Another group only received the control vehicle of LPC (ethanol) at day $-2,-1$ and 0 before sensitization by DNFB (group "DNFB"). The thickness of both ears was measured using a spring-loaded micrometer (J15 Blet SA, Lyon, France). Ear 
swelling was calculated by substracting ear thickness of the untreated right ear to ear thickness of the left ear. Vehicles alone did not induce ear swelling.

\subsection{Induction of a cytotoxic $T$ cell response}

Groups of five C57BL/6 mice were immunized twice at 7 days interval by injection in both hind footpads of $100 \mu \mathrm{g}$ of OVA mixed with $500 \mathrm{nmol}$ of LPC or with PBS. 7 days after the last injection, draining lymph nodes were removed. Cells were dissociated, washed and resuspended at $4 \times 10^{6}$ cells $/ \mathrm{ml}$ in complete medium for restimulation with E.G7-OVA cells. $\gamma$ irradiated E.G7-OVA cells $\left(2 \times 10^{5}\right.$ cells $\left./ \mathrm{ml}\right)$ were added to lymph node cells for a 5 dayrestimulation. Effector cells were then collected and incubated for cytotoxicity assay with $10^{4}$ E.G7-OVA target cells labelled with $\mathrm{Na}_{2}{ }^{51} \mathrm{CrO}_{4}$ for $1 \mathrm{~h}$ at $37^{\circ} \mathrm{C}$. After a 5 hour-incubation at various effector to target ratio $(\mathrm{E} / \mathrm{T})$, supernatants were collected and radioactivity was measured with a gamma counter (TopCount NXT, PerkinElmer, Boston, MA). Percent specific lysis was calculated as follows: $100 \mathrm{x}$ ([release by CTL - spontaneous release] / [maximal release - spontaneous release]). Maximal release was determined by addition of $2 \mathrm{~N}$ $\mathrm{HCl}$. Spontaneous release in the absence of CTL was $<15 \%$ of maximal release.

\subsection{Preventive and therapeutic anti-tumor therapy}

Treatment of established tumours: groups of C57BL/6 mice were injected s.c. into the right flank at day 0 with $1.5 \times 10^{4}$ E.G7-OVA cells. Mice were then injected with $100 \mu \mathrm{g}$ of OVA alone or $500 \mathrm{nmol}$ LPC alone or OVA+LPC or OVA+CFA in both flanks, at day 1, 8 and 15 . CFA was replaced by IFA in the second and third immunization. Preventive immunizations: groups of C57BL/6 mice were immunized at day -14 and -7 with s.c. injections of $100 \mu \mathrm{g}$ of OVA alone or $500 \mathrm{nmol} \mathrm{LPC}$ alone or OVA+LPC or OVA+CFA in both flanks. CFA was

replaced by IFA for the second injection. At day $0,1.5 \times 10^{4}$ E.G7-OVA cells were injected 
into the right flank. Tumour growth was followed and measured every 2 or 3 days. The tumour length (L) and width (W) were measured at different time points and tumour volume was determined by : $\left(\mathrm{Lx} \mathrm{W}^{2}\right) / 2$. Mice were sacrificed when the volume reached $4 \mathrm{~cm}^{3}$.

\subsection{Production of antibodies}

$\mathrm{BALB} / \mathrm{c}$ mice were immunized at day 0 in both hind footpads with $50 \mu \mathrm{g}$ of HEL mixed with PBS, LPC (500 nmol), Alum or CFA. At day 14, mice were injected s.c. on both flanks with the same mixtures except that CFA was replaced by IFA. Sera were collected at day 28 and titrated for HEL-specific antibodies by ELISA.

\subsection{ELISA}

96-well Nunc-Immuno plates (Nalge Nunc, Rochester, NY) were coated with $100 \mu \mathrm{g} / \mathrm{ml}$ HEL in $0,1 \mathrm{M}$ sodium bicarbonate buffer $\mathrm{pH} 9.5$ at $4{ }^{\circ} \mathrm{C}$ overnight, washed twice with $\mathrm{PBS} / 0.05 \%$ Tween 20 and saturated with PBS / 5\% BSA for $30 \mathrm{~min}$ at $37^{\circ} \mathrm{C}$. Sera were incubated for $1 \mathrm{~h}$ at $37^{\circ} \mathrm{C}$. After washing, HEL-specific Ig were detected by alkaline phosphatase-conjugated Abs diluted in PBS. Goat anti-mouse $\operatorname{Ig}(\mathrm{H}+\mathrm{L})$, specific for $\operatorname{IgG}+\operatorname{Ig} M+\operatorname{IgA}$, was from Sigma and used at 1:10000. Anti-mouse IgG1 and IgG2a were from Rockland (Gilbertsville, PA, USA) and used at 1:10000 and 1:4000 respectively. Secondary Abs were incubated for 1

$\mathrm{h}$ at $37^{\circ} \mathrm{C}$. The colorimetric assay was developed with $2 \mathrm{mg} / \mathrm{ml}$ para-nitrophenyl phosphate (Sigma) in 0,1 M triethanolamine $\mathrm{pH} 9.6 / 1 \mathrm{mM} \mathrm{MgCl}_{2}$, for $30 \mathrm{~min}$ at $37^{\circ} \mathrm{C}$. Absorbance at $405 \mathrm{~nm}$ was determined using a MRX microplate reader (Dynex Technologies, Worthing, U.K.). 


\section{Results}

\subsection{LPC primes specific $T$ cell responses in vivo}

The following experiments were designed to explore the ability of LPC to prime Ag-specific $\mathrm{T}$ cell responses in mice. Immunization experiments were conducted with $\mathrm{BALB} / \mathrm{c}$ mice that were injected once in the footpads with a mixture of LPC and HEL. After 10 days, the popliteal draining lymph nodes were collected and cells were restimulated ex-vivo for 4 days with the indicated doses of HEL. The capacity of $\mathrm{T}$ cells to respond to Ag restimulation was analyzed by measuring their proliferation. Figure 1A shows that $\mathrm{T}$ cells from mice immunized with 30 to $100 \mu \mathrm{g}$ HEL mixed with $500 \mathrm{nmol}$ LPC could respond to antigenic restimulation in vitro, indicating that sufficient naive HEL-specific T cells have been primed in vivo. Neither immunization with $100 \mu \mathrm{g}$ of HEL without LPC nor injection of LPC alone could induce HEL-specific T cell priming in vivo (Fig. 1A). Immunization with 3 to $10 \mu \mathrm{g}$ HEL plus LPC was not sufficient to induce a good priming of HEL-specific $\mathrm{T}$ cells under these experimental conditions. The adjuvant effect of LPC was dose-dependent (Fig 1B) with optimal priming obtained with $500 \mathrm{nmol}$ LPC and $50 \mu \mathrm{g}$ HEL. Mann-Whitney rank test indicated that proliferation indexes obtained from mice immunized with HEL $+500 \mathrm{nmol} \mathrm{LPC}(\mathrm{n}=14)$ were significantly higher than those obtained from mice immunized with HEL alone ( $\mathrm{n}=11)$ with $\mathrm{p}<0.01$. Thus, $\mathrm{LPC}$ is a natural lipid that can induce in vivo the priming of naive $\mathrm{T}$ cells when co-injected with an $\mathrm{Ag}$ in a single intra-footpad injection.

In previous reports, we showed that the action of LPC on DC in vitro could be blocked by Intralipid (IL), a therapeutic lipid emulsion currently used for parenteral nutrition in case of septic shock [8]. Figure 1C shows that co-injection of IL with HEL+LPC strongly inhibited 
the induction of the HEL-specific T cell response, indicating that IL can antagonize in vivo the immunostimulating effect of LPC.

The ability of LPC to stimulate $\mathrm{T}$ cell responses in vivo was then extended to a well characterized model of contact hypersensitivity (CHS) to the DNFB hapten. CHS is a skin inflammatory reaction that occurs at the site of hapten epicutaneous application and which is mediated by hapten-specific T cells [37]. Upon skin painting, the hapten is taken up by skin DC which migrate to proximal lymph nodes and activate specific T cells. Since the hapten can stay in the skin for a few days in its antigenic form, effector $\mathrm{CD}^{+} \mathrm{T}$ cells are recruited and activated in the dermis and induce CHS through a process involving cytotoxicity and IFN $\gamma$ synthesis $[38,39]$. We used suboptimal concentrations of DNFB so that the CHS reaction observed at day 5 was only moderate in intensity and magnitude (Fig. 1D). Epicutaneous application of LPC once daily for three days before DNFB sensitization dramatically increased the CHS reaction to suboptimal concentrations of DNFB. Application of LPC alone did not induce ear swelling (data not shown).

Since activated hapten-specific $\mathrm{CD}^{+} \mathrm{T}$ cells in the skin are the effectors of the CHS reaction to DNFB, these results suggested that LPC could stimulate hapten-specific CTL priming and/or recruitment. Therefore, we analyzed the activation of $\mathrm{CD}^{+} \mathrm{T}$ cells in a model where cytotoxicity can be measured.

\subsection{LPC induces a cytotoxic $T$ cell response in vivo}

These experiments were designed to compare the efficiency of CTL priming when mice are immunized with OVA supplemented with LPC, Freund's Adjuvant or Alum. Immunization with CFA was used as a positive control of CTL activation. In contrast, Alum is an efficient inducer of humoral responses but a poor inducer of CTL responses. C57BL/6 mice were 
immunized twice at one week interval by injection in the footpads of OVA mixed with the various adjuvants. One week after the second immunization, lymph nodes were collected and cells were restimulated for 5 days by irradiated E.G7-OVA cells. The E.G7-OVA tumour cell line derives from the C57BL/6 lymphoma EL4 cell line that has been transfected with the OVA cDNA. These cells express OVA endogenously and present OVA peptides on MHCClass I molecules. CTL activity was assessed by ${ }^{51} \mathrm{Cr}$ release assay using E.G7-OVA cells as target. Figure 1E shows that immunization of mice with OVA+LPC generates OVA-specific cytotoxic T cells with an efficiency similar to immunization with OVA+CFA. As expected, immunization with OVA alone or in combination with Alum was inefficient to generate CTL.

\subsection{LPC elicits preventive and therapeutic anti-tumour responses}

To further analyze the ability of LPC to prime an Ag-specific response, we asked whether OVA+LPC immunization could prevent or reduce the growth of the E.G7-OVA tumour cell line in C57BL/6 syngeneic mice. In this model, C57BL/6 mice were immunized preventively with OVA alone, LPC alone, OVA+LPC or OVA+CFA, at day -14 and -7 before tumour challenge at day 0 with $1.5 \times 10^{4}$ E.G7-OVA cells injected s.c. Control mice that received OVA alone or LPC alone developed solid tumours between day 9 and day 16 (Fig. 2). In mice immunized with LPC+OVA, tumour development was delayed and even prevented until day 30 for one third of the mice that remained tumour free at the autopsy (Fig. 2). The protection induced by immunization with LPC was similar to that provided by immunization with CFA, an adjuvant known to stimulate the CTL response with high efficiency.

In a second set of experiments, therapeutic immunizations were performed against OVA as a tumour Ag using LPC or CFA as adjuvant. The tumour cells were first injected at day 0 and

mice were immunized 3 times at day 1, 8 and 15 by s.c. injection of OVA alone, LPC alone, 
OVA + LPC or OVA+CFA. In control mice injected with OVA or LPC alone, the tumours were detectable at day 10 and presented an exponential growth (Fig. 3A,B). When mice received OVA + LPC, tumour growth was delayed by 7 days (Fig. 3C, E). At day 17, the tumour mean size of mice immunized with OVA+LPC was significantly reduced compared to control mice that received OVA alone $(\mathrm{p}<0.01)$. Immunization with OVA+CFA also strongly reduced tumour growth (Fig. 3D).

Although an important delay in tumour appearance was observed in mice immunized with $\mathrm{OVA}+\mathrm{LPC}$ and OVA $+\mathrm{CFA}$, the growth rate did not seem to be significantly different from control once the tumour has started to grow.

\subsection{LPC initiates the production of Ag-specific antibodies}

The data presented above indicate that LPC can prime T cell responses against different Ags. The ability of LPC to initiate a B cell response was then tested by immunizing BALB/c mice against HEL and measuring HEL-specific Abs by ELISA. Immunizations with HEL alone was not followed by the production of Abs whereas immunizations with HEL + CFA induced a massive secretion of anti-HEL Ig (Fig. 4A) with a mean titer reaching $10^{4}$ (Fig. 4B). Immunizations with HEL+LPC led to the production of HEL-specific Ig (Fig. 4A) with an intermediate titer (Fig. 4B). These results were highly significant $(\mathrm{p}<0.02)$ and similar to those obtained following immunization with HEL+Alum (data not shown). The characterization of IgG isotypes showed that LPC and Alum induced very similar responses with high production of anti-HEL IgG1 but no anti-HEL IgG2a (Fig. 4C). As previously described for BALB/c mice [40,41], only CFA induced an important secretion of both IgG1 and IgG2a (Fig. 4D). 


\section{Discussion}

The APR is a transient reaction of the host to an aggression that results in important modifications of the concentration of acute phase reactants. Native lipoproteins whose function is to transport and distribute non polar lipids throughout the organism acquire additional function during the APR. Indeed, acute phase lipoproteins can be submitted to biochemical modifications that lead to the production of bioactive molecules. Among these molecules, LPC is known to be a pro-inflammatory lysophospholipid and to stimulate the generation of mature DC from differentiating monocytes in vitro [8]. This raised the intriguing possibility that LPC could be an endogenous signal of danger, favouring the activation of the adaptive arm of the immune response, that could be of interest for the development of new immunotherapy and vaccination procedures. It is shown here that LPC can initiate both humoral and cellular Ag-specific adaptive responses when injected subcutaneously with an $\mathrm{Ag}$ that does not elicit by itself an immune response. The action of LPC on T cell priming could be demonstrated using several immunization procedures against HEL, OVA or the hapten DNFB. LPC enhanced the CHS response to DNFB, a reaction that requires the activation of DNFB-specific $\mathrm{CD}^{+} \mathrm{T}$ cells and their recruitment in the skin [39]. Ag-specific T cell proliferation and CTL generation was also observed after immunization with HEL or OVA mixed with LPC. These data suggest that LPC induces the presentation of exogenous Ag on MHC-Class I molecules, a property mainly devoted to mature DC. Immunization with OVA+LPC also inhibited the development of $\mathrm{OVA}^{+}$MHC-class I-positive tumours, in a preventive and therapeutic manner. LPC injected in mixture with a protein Ag was able to initiate an antibody specific response with production of IgG1. Although it was previously shown that LPC could enhance antibody production that was naturally induced by sheep erythrocytes in mice [32], this is the first report that LPC does not only increase 
antibody production but can also efficiently prime B cell responses. Although the absence of IgG2a is more in favour of a Th2-type response, the overall data indicate that LPC can stimulate a well balanced immune response leading to both cellular and humoral immunity. Several receptors could account for the detection of LPC in mice. The receptor G2A is involved in the LPC-induced protection of mice from experimental sepsis [28]. Our preliminary results show that blocking Abs administered as described in the model of experimental sepsis did not affect the induction of a $\mathrm{T}$ cell response by LPC, suggesting that G2A is unlikely playing a major role in this process. Other known LPC receptors could mediate the action of LPC such as the G-protein coupled receptors GPR4 and PAF-receptor $[23,42,43]$ and the scavenger receptor LOX-1 [44].

Alum is associated with a Th2-oriented immune response characterized by a strong humoral response but a poor cellular immunity. Therefore, Alum is a good adjuvant when protection mainly relies on neutralizing antibodies. However, subcutaneous or intradermal injection of Alum-based vaccine may favour the development of granulomas and this adjuvant is associated with increased $\operatorname{IgE}$ production and allergenicity (for review see [45]). The observation that LPC stimulates antibody production with an efficiency similar to that of Alum, combined with an active cellular immunity opens interesting perspectives in the field of vaccination. It suggests that LPC or related molecules naturally generated during the APR could be introduced in future vaccination formulations against tumours or viruses. The local effect of intracutaneous injection of high concentration of LPC has been studied in humans. No toxicity was observed but a moderate erythema and oedema occurred that rapidly disappeared in 4 hours [27]. Local cellular infiltrate was composed of monocytes, neutrophils and lymphocytes. The ability of LPC to naturally penetrate the skin as shown in the CHS experiments suggests that LPC could be used for transcutaneous immunizations. This 
possibility strengthen the therapeutic potential of LPC that nonetheless needs to be further investigated in both animals and humans.

During the APR, increased oxidation of LDL and secretion of $\mathrm{PLA}_{2}$ both favour the production of LPC and other biologically active lipids that have the ability to stimulate DC maturation $[8,46]$. Elevated levels of active LPC in the blood can result from oxidation or $\mathrm{PLA}_{2}$ hydrolysis of PC from lipoproteins accompanied by a decrease in the concentration of LPC inhibitors, albumin and native LDL. In inflamed peripheral tissues, increased secretion of inflammatory PLA 2 may result in local burst of LPC by hydrolysis of cell membrane PC. Moreover, pro-oxidant molecules generated by the inflammation can favour the accumulation of oxLDL and LPC in the tissue. This process has been described during atherosclerosis, which is a chronic inflammatory disease of arterial wall, where high amounts of LPC are found in atherosclerotic lesions [47]. LPC synthesis is also triggered by apoptosis through the activation of intracellular $\mathrm{PLA}_{2}$. This lipid that diffuses in the microenvironment is a chemoattractant for phagocytes and antigen presenting cells [11]. Moreover, LPC exposure at the cell surface results in the binding of natural $\operatorname{IgM}$ and complement activation, therefore favouring rapid elimination of apoptotic corpses [12]. It appears that membrane modifications during apoptosis produce a variety of lipids with distinct immunoregulatory functions. Clearly, mechanisms of generation of LPC and other bioactive lipids is an important issue that deserves further investigation. These molecules that are easy to synthesized in vitro and display immunoregulatory functions, could be used in human.

In vivo, LPC action on the immune system could take place at different levels since this lipid displays diverse effects on various cell types in vitro. LPC is a chemoattractant, enhancing the recruitment of monocytes, neutrophils and lymphocytes [13,19,27]. Hence, elevated levels of LPC in inflamed tissues may enhance the recruitment of blood monocytes and their differentiation to mature DC as previously shown in vitro [8]. LPC also induces the secretion 
of pro-inflammatory molecules by endothelial cells, creating a local environment that may favour DC activation. Therefore, LPC may stimulate the maturation and migration of on increasing number of $\mathrm{DC}$ to the draining lymph nodes where they can prime naive $\mathrm{T}$ lymphocytes. This chemoattractant lipid may also enhance the recruitment of activated $\mathrm{T}$ lymphocytes in the injured tissue. In addition, LPC negatively regulates T cell proliferation induced by mitogenic signals [29]. LPC may thus increase the specificity of $\mathrm{T}$ cell activation of newly recruited $\mathrm{T}$ lymphocytes and prevent bystander proliferation.

Therefore, by controlling the production of bioactive lipids, the APR and apoptosis now appear to be directly involved in the regulation of the adaptive immune system. Inhibition of the effect of oxLDL and LPC in vitro and in vivo by native LDL and Intralipid [7-9], highlights the central role of the balance between native and APR lipids in this process. A lipidomic analysis of the APR and apoptotic cells should help in our understanding of these new immunoregulatory pathways and should open therapeutic perspectives for the use of endogeneous lipids in immunotherapy and vaccination. 


\section{References}

[1] Baumann, H. \& Gauldie, J. The acute phase response. Immunol Today 1994, 15(2), 74-80.

[2] Gabay, C. \& Kushner, I. Acute-phase proteins and other systemic responses to inflammation. N Engl J Med 1999, 340(6), 448-454.

[3] Cabana, V.G., Siegel, J.N. \& Sabesin, S.M. Effects of the acute phase response on the concentration and density distribution of plasma lipids and apolipoproteins. J Lipid Res 1989, 30(1), 39-49.

[4] Steinberg, D. Low density lipoprotein oxidation and its pathobiological significance. $J$ Biol Chem 1997, 272(34), 20963-20966.

[5] Witztum, J.L. \& Steinberg, D. Role of oxidized low density lipoprotein in atherogenesis. J Clin Invest 1991, 88(6), 1785-1792.

[6] Memon, R.A., Staprans, I., Noor, M. et al. Infection and inflammation induce LDL oxidation in vivo. Arterioscler Thromb Vasc Biol 2000, 20(6), 1536-1542.

[7] Perrin-Cocon, L., Coutant, F., Agaugue, S., Deforges, S., Andre, P. \& Lotteau, V. Oxidized low-density lipoprotein promotes mature dendritic cell transition from differentiating monocyte. J Immunol 2001, 167(7), 3785-3791.

[8] Coutant, F., Perrin-Cocon, L., Agaugue, S., Delair, T., Andre, P. \& Lotteau, V. Mature dendritic cell generation promoted by lysophosphatidylcholine. J Immunol 2002, 169(4), 1688-1695.

[9] Coutant, F., Agaugue, S., Perrin-Cocon, L., Andre, P. \& Lotteau, V. Sensing environmental lipids by dendritic cell modulates its function. J Immunol 2004, 172(1), 54-60. 
[10] Steinbrecher, U.P. \& Pritchard, P.H. Hydrolysis of phosphatidylcholine during LDL oxidation is mediated by platelet-activating factor acetylhydrolase. J Lipid Res 1989 , 30(3), 305-315.

[11] Lauber, K., Bohn, E., Krober, S.M. et al. Apoptotic cells induce migration of phagocytes via caspase-3-mediated release of a lipid attraction signal. Cell 2003, 113(6), 717-730.

[12] Kim, S.J., Gershov, D., Ma, X., Brot, N. \& Elkon, K.B. I-PLA(2) activation during apoptosis promotes the exposure of membrane lysophosphatidylcholine leading to binding by natural immunoglobulin $\mathrm{M}$ antibodies and complement activation. $J$ Exp Med 2002, 196(5), 655-665.

[13] Quinn, M.T., Parthasarathy, S. \& Steinberg, D. Lysophosphatidylcholine: a chemotactic factor for human monocytes and its potential role in atherogenesis. Proc Natl Acad Sci U S A 1988, 85(8), 2805-2809.

[14] Lauber, K., Blumenthal, S.G., Waibel, M. \& Wesselborg, S. Clearance of apoptotic cells: getting rid of the corpses. Mol Cell 2004, 14(3), 277-287.

[15] McMurray, H.F., Parthasarathy, S. \& Steinberg, D. Oxidatively modified low density lipoprotein is a chemoattractant for human T lymphocytes. J Clin Invest 1993, 92(2), 1004-1008.

[16] Radu, C.G., Yang, L.V., Riedinger, M., Au, M. \& Witte, O.N. T cell chemotaxis to lysophosphatidylcholine through the G2A receptor. Proc Natl Acad Sci U S A 2004, 101(1), 245-250.

[17] Kume, N. \& Gimbrone, M.A., Jr. Lysophosphatidylcholine transcriptionally induces growth factor gene expression in cultured human endothelial cells. J Clin Invest 1994, 93(2), 907-911. 
[18] Nakano, T., Raines, E.W., Abraham, J.A., Klagsbrun, M. \& Ross, R. Lysophosphatidylcholine upregulates the level of heparin-binding epidermal growth factor-like growth factor mRNA in human monocytes. Proc Natl Acad Sci U S A 1994, 91(3), 1069-1073.

[19] Kume, N., Cybulsky, M.I. \& Gimbrone, M.A., Jr. Lysophosphatidylcholine, a component of atherogenic lipoproteins, induces mononuclear leukocyte adhesion molecules in cultured human and rabbit arterial endothelial cells. J Clin Invest 1992, 90(3), 1138-1144.

[20] Takahara, N., Kashiwagi, A., Maegawa, H. \& Shigeta, Y. Lysophosphatidylcholine stimulates the expression and production of MCP- 1 by human vascular endothelial cells. Metabolism 1996, 45(5), 559-564.

[21] Jing, Q., Xin, S.M., Zhang, W.B., Wang, P., Qin, Y.W. \& Pei, G. Lysophosphatidylcholine activates p38 and p42/44 mitogen-activated protein kinases in monocytic THP-1 cells, but only p38 activation is involved in its stimulated chemotaxis. Circ Res 2000, 87(1), 52-59.

[22] Ousman, S.S. \& David, S. Lysophosphatidylcholine induces rapid recruitment and activation of macrophages in the adult mouse spinal cord. Glia 2000, 30(1), 92-104.

[23] Ogita, T., Tanaka, Y., Nakaoka, T. et al. Lysophosphatidylcholine transduces Ca2+ signaling via the platelet- activating factor receptor in macrophages. Am J Physiol 1997, 272(1 Pt 2), H17-24.

[24] Oestvang, J., Anthonsen, M.W. \& Johansen, B. Role of secretory and cytosolic phospholipase $\mathrm{A}(2)$ enzymes in lysophosphatidylcholine-stimulated monocyte arachidonic acid release. FEBS Lett 2003, 555(2), 257-262.

[25] Ngwenya, B.Z. \& Yamamoto, N. Activation of peritoneal macrophages by lysophosphatidylcholine. Biochim Biophys Acta 1985, 839(1), 9-15. 
[26] Whalen, M.M., Doshi, R.N., Bader, B.W. \& Bankhurst, A.D. Lysophosphatidylcholine and arachidonic acid are required in the cytotoxic response of human natural killer cells to tumor target cells. Cell Physiol Biochem 1999, 9(6), 297-309.

[27] Ryborg, A.K., Deleuran, B., Sogaard, H. \& Kragballe, K. Intracutaneous injection of lysophosphatidylcholine induces skin inflammation and accumulation of leukocytes. Acta Derm Venereol 2000, 80(4), 242-246.

[28] Yan, J.J., Jung, J.S., Lee, J.E. et al. Therapeutic effects of lysophosphatidylcholine in experimental sepsis. Nat Med 2004, 10, 161-167.

[29] Weng, Z., Fluckiger, A.C., Nisitani, S. et al. A DNA damage and stress inducible G protein-coupled receptor blocks cells in G2/M. Proc Natl Acad Sci U S A 1998, 95(21), 12334-12339.

[30] Kabarowski, J.H., Zhu, K., Le, L.Q., Witte, O.N. \& Xu, Y. Lysophosphatidylcholine as a ligand for the immunoregulatory receptor G2A. Science 2001, 293(5530), 702705.

[31] Witte, O.N., Kabarowski, J.H., Xu, Y., Le, L.Q. \& Zhu, K. Retraction. science 2005, 307(5707), 206b.

[32] Ngwenya, B.Z. \& Foster, D.M. Enhancement of antibody production by lysophosphatidylcholine and alkylglycerol. Proc Soc Exp Biol Med 1991, 196(1), 6975.

[33] Arnold, B., Staber, F.G. \& Miller, J.F. Lysolecithin analogs as adjuvants in delayedtype hypersensitivity in mice. II. Studies on the mode of action. Eur J Immunol 1979, 9(5), 367-370. 
[34] Arnold, B., Miller, J.F. \& Weltzien, H.U. Lysolecithin analogs as adjuvants in delayed-type hypersensitivity in mice. I. Characterization of the adjuvant effect. Eur $J$ Immunol 1979, 9(5), 363-366.

[35] Matzinger, P. Tolerance, danger, and the extended family. Annu Rev Immunol 1994, 12, 991-1045.

[36] Matzinger, P. An innate sense of danger. Semin Immunol 1998, 10(5), 399-415.

[37] Saint-Mezard, P., Krasteva, M., Chavagnac, C. et al. Afferent and efferent phases of allergic contact dermatitis (ACD) can be induced after a single skin contact with haptens: evidence using a mouse model of primary ACD. J Invest Dermatol 2003, $120(4), 641-647$.

[38] Kehren, J., Desvignes, C., Krasteva, M. et al. Cytotoxicity is mandatory for CD8(+) T cell-mediated contact hypersensitivity. $J$ Exp Med 1999, 189(5), 779-786.

[39] Akiba, H., Kehren, J., Ducluzeau, M.T. et al. Skin inflammation during contact hypersensitivity is mediated by early recruitment of CD8+ T cytotoxic 1 cells inducing keratinocyte apoptosis. J Immunol 2002, 168(6), 3079-3087.

[40] Ebhardt, M.B., Shive, C.L., Guardia, R., Gapin, L., Boehm, B.O. \& Forsthuber, T.G. Immunological adjuvants efficiently induce antigen-specific $\mathrm{T}$ cell responses in old mice: implications for vaccine adjuvant development in aged individuals. Cell Immunol 2002, 215(1), 87-97.

[41] Chu, R.S., Targoni, O.S., Krieg, A.M., Lehmann, P.V. \& Harding, C.V. CpG oligodeoxynucleotides act as adjuvants that switch on T helper 1 (Th1) immunity. $J$ Exp Med 1997, 186(10), 1623-1631.

[42] Zhu, K., Baudhuin, L.M., Hong, G. et al. Sphingosylphosphorylcholine and lysophosphatidylcholine are ligands for the G protein-coupled receptor GPR4. J Biol Chem 2001, 276(44), 41325-41335. 
[43] Huang, Y.H., Schafer-Elinder, L., Wu, R., Claesson, H.E. \& Frostegard, J. Lysophosphatidylcholine (LPC) induces proinflammatory cytokines by a plateletactivating factor (PAF) receptor-dependent mechanism. Clin Exp Immunol 1999, 116(2), 326-331.

[44] Aoyama, T., Chen, M., Fujiwara, H., Masaki, T. \& Sawamura, T. LOX-1 mediates lysophosphatidylcholine-induced oxidized LDL uptake in smooth muscle cells. FEBS Lett 2000, 467(2-3), 217-220.

[45] Gupta, R.K. Aluminum compounds as vaccine adjuvants. Adv Drug Deliv Rev 1998, 32(3), 155-172.

[46] Perrin-Cocon, L., Agaugue, S., Coutant, F. et al. Secretory phospholipase A2 induces dendritic cell maturation. Eur J Immunol 2004, 34, 2293-2302.

[47] Portman, O.W. \& Alexander, M. Lysophosphatidylcholine concentrations and metabolism in aortic intima plus inner media: effect of nutritionally induced atherosclerosis. J Lipid Res 1969, 10(2), 158-165. 


\section{Acknowledgements}

We thank A. Masurel for technical assistance. This work was supported by ANRS (Agence Nationale de Recherche sur le Sida) (HC EP 05), INSERM (Institut National de la Santé et de la Recherche Médicale) and bioMérieux SA. F. Coutant was a recipient of a "Fondation pour la Recherche Médicale” doctoral scholarship. S. Agaugué is a recipient of a Association pour la Recherche contre le Cancer doctoral scholarship. 


\section{Figure legends}

Fig. 1. LPC stimulates Ag-specific $\mathrm{T}$ cell responses in vivo. (A) BALB/c mice were immunized with the indicated doses of $\operatorname{HEL}(0,3,10,30$ or $100 \mu \mathrm{g} /$ footpad) mixed with LPC (500 nmol/footpad). Control mice were immunized with $100 \mu \mathrm{g}$ of HEL in PBS, without LPC. At d10, cells from draining lymph nodes were restimulated in vitro with HEL for 4 days at the indicated concentration and proliferation of $\mathrm{T}$ cells was measured by ${ }^{3} \mathrm{H}$-Thymidine incorporation. Mean +/- SD of triplicata is shown for a representative experiment out of five. (B) Mice were immunized with $50 \mu \mathrm{g}$ of HEL mixed with 0,250 or $500 \mathrm{nmol}$ of LPC. At day 10, cells from the draining lymph nodes were restimulated with HEL for 4 days and proliferation of $\mathrm{T}$ cells was measured by ${ }^{3} \mathrm{H}$-Thymidine incorporation. Mean +/- SD of triplicata is shown for a representative experiment out of five. (C) Intralipid inhibits $\mathrm{T}$ cell priming by LPC. Mice were immunized with $50 \mu \mathrm{g}$ HEL alone (HEL), HEL + Intralipid 20\% $(\mathrm{HEL}+\mathrm{IL}), \mathrm{HEL}+500 \mathrm{nmol} \mathrm{LPC}(\mathrm{HEL}+\mathrm{LPC})$ or HEL + Intralipid 20\% + LPC (HEL + LPC + IL). At d10, cells from draining lymph nodes were restimulated ex vivo with $50 \mu \mathrm{M}$ HEL for 4 days and proliferation of T cells was measured. Mean ${ }^{3} \mathrm{H}$-Thymidine incorporation +/- SD for each group of mice is shown for a representative experiment out of three. (D) LPC enhances DNFB specific-T cell response. One group was treated with LPC, applied once daily on the left ear (500 nmol) for 3 days, while another group received only ethanol. DNFB $(0,25 \%)$ was applied at day 0 on the left ear 15 min after the last application of LPC $(\mathrm{LPC}+\mathrm{DNFB})$ or ethanol (DNFB). Ear swelling was measured at day -2 before application, at day 0 and thereafter from day 5 to day 9 . Mean ear swelling \pm SD for each group of five mice of a representative experiment out of three. (E) LPC induces cytotoxic T cell response. C57BL/6 mice were immunized twice at one week interval by injection in both hind footpads of $100 \mu \mathrm{g}$ OVA with or without $500 \mathrm{nmol}$ LPC. One week later, popliteal lymph node cells 
were collected and cultured with irradiated E.G7-OVA cells for 5 days. Cytotoxic activity was measured by a standard ${ }^{51} \mathrm{Cr}$ release assay at the indicated effector to target cells ratio (E/T ratio). Data are expressed as means of triplicate determinations and are representative of three independent experiments. SD was less than $10 \%$.

Fig. 2. LPC induces a preventive anti-tumour response. Groups of C57BL/6 mice were immunized at day -14 and -7 by s.c. injection in both flanks of $100 \mu \mathrm{g}$ OVA without adjuvant $(\bullet), 500$ nmol LPC (匹), OVA + LPC (•) or OVA + CFA ( $\square)$. At day 0, mice were challenged by s.c. injection of $1.5 \times 10^{4}$ E.G7 cells into the right flank. Tumour appearance was monitored every 2-3 days. Data from a representative experiment with 9-10 mice per group out of three.

Fig. 3. LPC induces a therapeutic anti-tumour response. Groups of C57BL/6 mice received $1.5 \times 10^{4}$ E.G7 cells via s.c. injection at day 0 and were immunized at day 1,8 and 15 by s.c. injection in both flanks of $100 \mu \mathrm{g}$ OVA alone (A), $500 \mathrm{nmol}$ LPC (B), OVA + LPC (C) or OVA + CFA (D). Tumour volume was measured at indicated days. Dots represent each individual mouse and the curve shows the evolution of the mean size for each group. The results of one out of three independent experiments are shown. (E) Mean tumour size \pm SD for each group of five mice is shown at day 17. Statistical significance was determined with Student's t-test, compared with OVA group

Fig. 4. LPC induces the production of HEL-specific antibodies. Mice were immunized twice with $100 \mu \mathrm{g}$ HEL with or without LPC or Alum or CFA at 2 weeks interval. Two weeks after the second injection, sera were collected and titrated for HEL-specific antibodies. Data are representative of five independent experiments. (A) Titration of HEL-specific total Ig. Dots represent individual mice and the curve shows the mean value for each group of mice. (B) 
HEL-specific antibody titers are calculated by determining the serum dilution giving $50 \%$ of the maximal O.D. Dots represent individual mice. Statistical significance was determined with Student's t-test, compared with HEL group (C) Titration of HEL-specific IgG1. Data represent mean $\pm \mathrm{SD}$ of groups of five mice. (D) Antibody titers of HEL-specific IgG1 and IgG2a, determined as the serum dilution giving $50 \%$ of the maximal O.D. Data represent mean $\pm \mathrm{SD}$ of groups of five mice. 

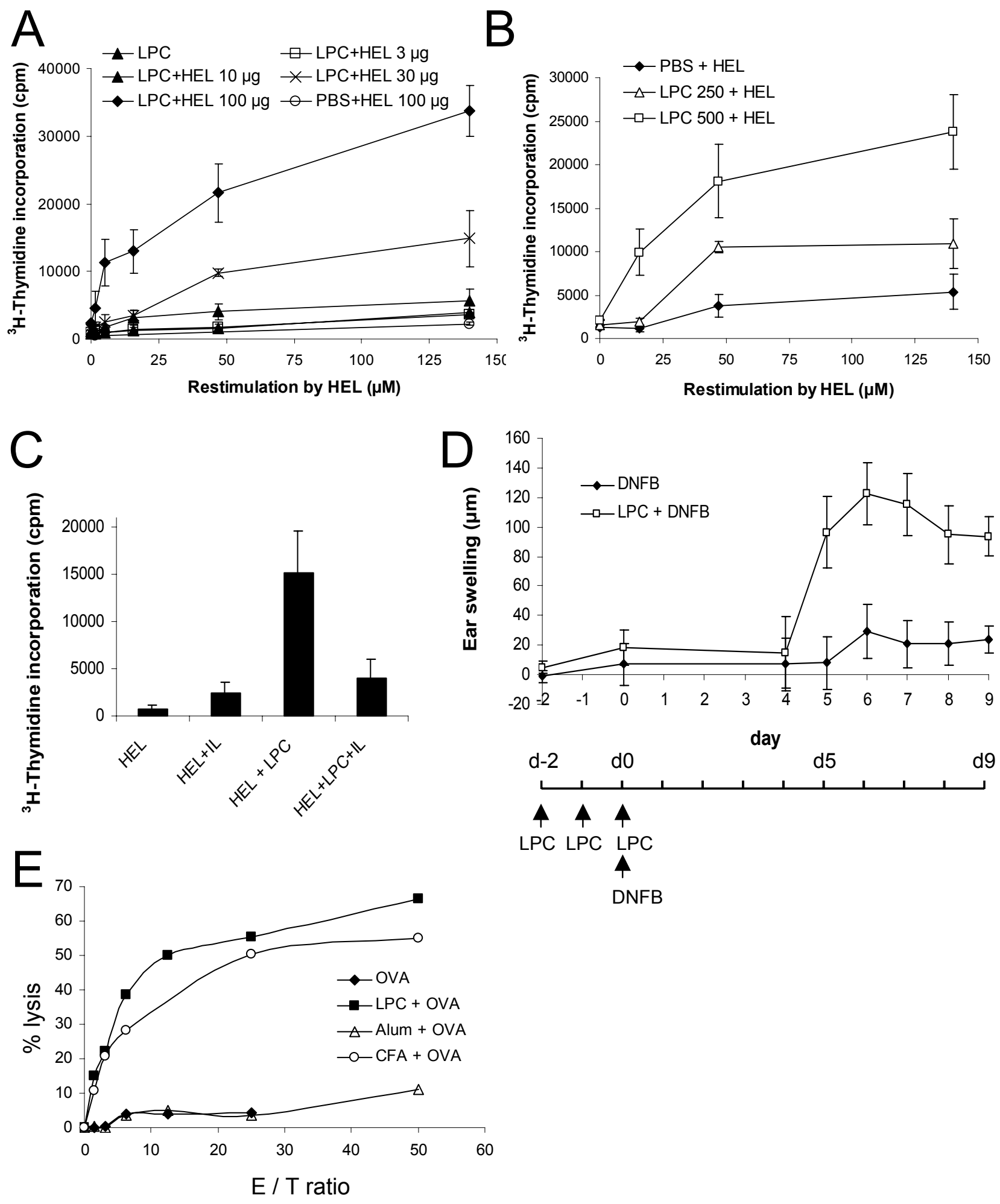

Figure 1 


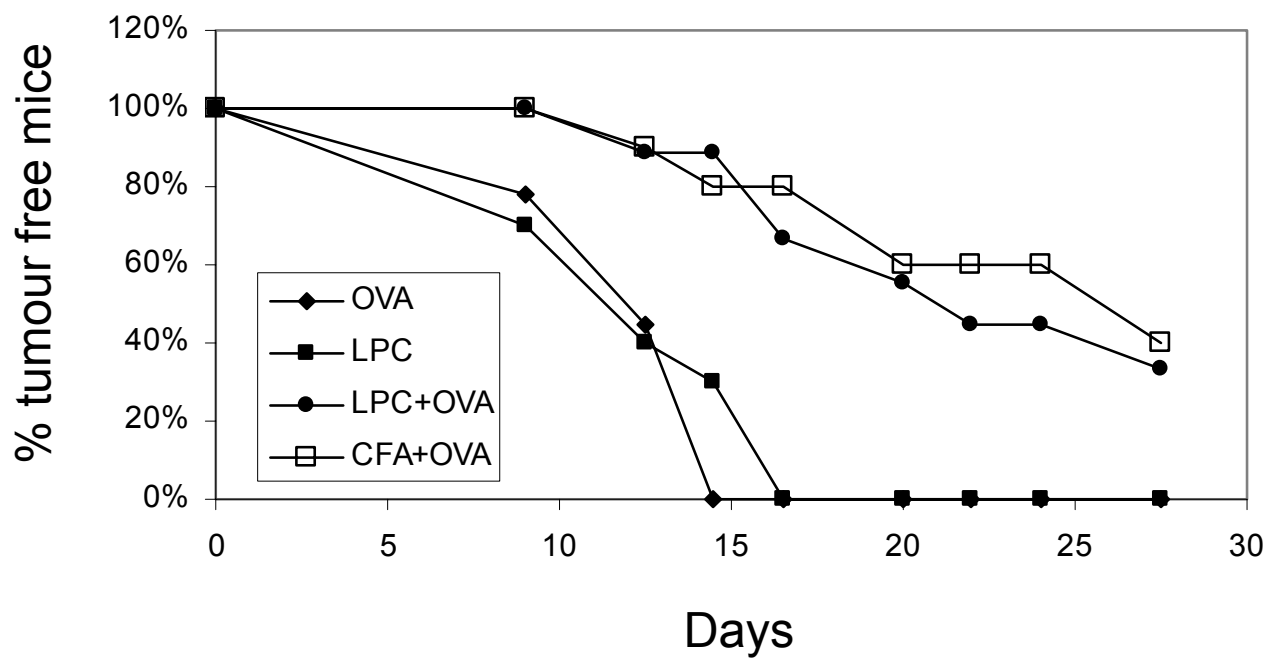

Figure 2 

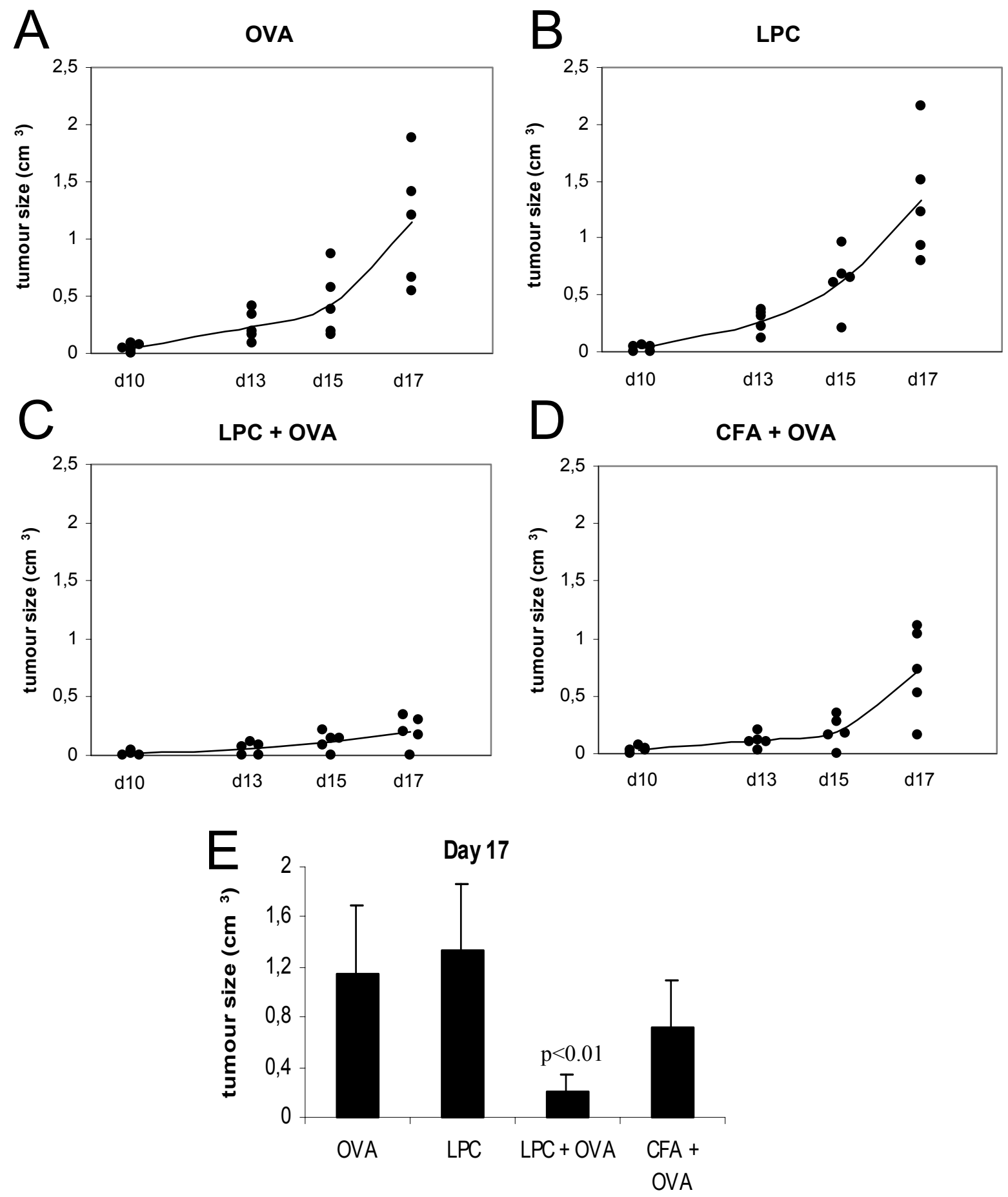

Figure 3 

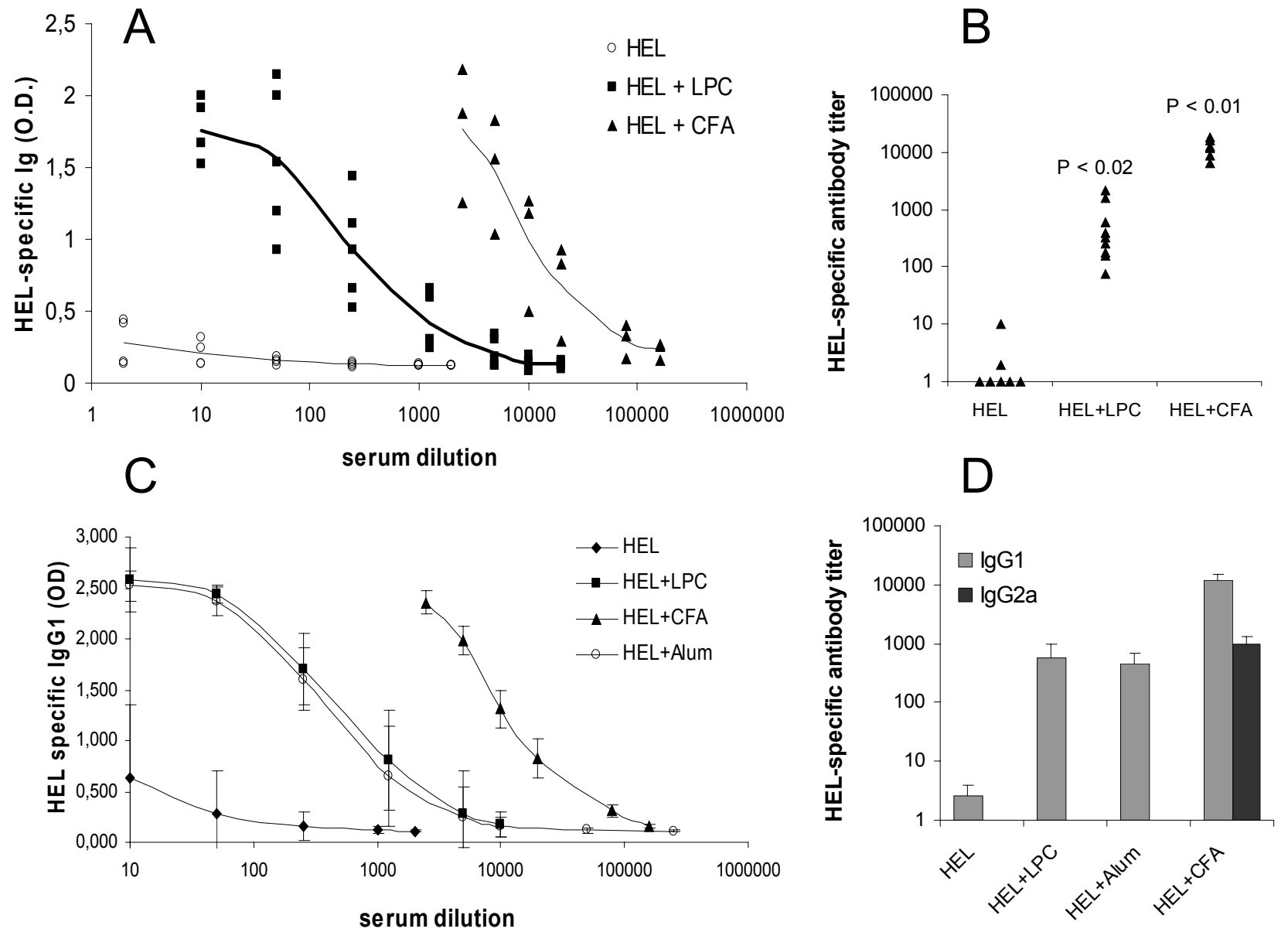

Figure 4 